\title{
Behavioral and Neural Enhancing Effects of a Summer Treatment Program in Children with Attention Deficit Hyperactivity Disorder
}

\author{
Akira Yasumura ${ }^{1,2 *}$, Kotaro Yuge ${ }^{3}$, Chiyomi Egamiं, Chizuru Anai5, Akiko Mukasa5, \\ Yushiro Yamashita ${ }^{3,5}$, Masumi Inagaki ${ }^{1}$ \\ ${ }^{1}$ Department of Developmental Disorders, National Institute of Mental Health, National Center of Neurology \\ and Psychiatry, Tokyo, Japan \\ ${ }^{2}$ Department of Neuropsychiatry, The University of Tokyo Hospital, Tokyo, Japan \\ ${ }^{3}$ Department of Pediatrics and Child Health, Kurume University School of Medicine, Fukuoka, Japan \\ ${ }^{4}$ Faculty of Nursing, Fukuoka Prefectural University, Fukuoka, Japan \\ ${ }^{5}$ NPO Kurume summer treatment program, Fukuoka, Japan \\ Email: "a-yasumura@umin.ac.jp
}

Received 4 February 2016; accepted 11 March 2016; published 15 March 2016

Copyright (C) 2016 by authors and Scientific Research Publishing Inc.

This work is licensed under the Creative Commons Attribution International License (CC BY).

http://creativecommons.org/licenses/by/4.0/

(c) (i) Open Access

\section{Abstract}

Deficiency in executive functioning is a core symptom of attention deficit hyperactivity disorder (ADHD). The brain part responsible for executive functions is the prefrontal cortex (PFC). Although drug-based interventions can improve PFC activity, reports on PFC activity being improved by behavioral treatment are lacking. We evaluated whether a summer treatment program (STP) administering comprehensive behavioral treatment would increase PFC activity in children with ADHD. We examined behavioral and neural changes in 20 children before and after the STP, conducted over a 2-week period. We asked the parents/guardians to complete the Swanson, Nolan, and Pelham IV scale to assess severity of ADHD. The main task evaluating executive control was the reverse Stroop task. To examine changes in physiological indices, we used near-infrared spectroscopy to measure changes in PFC activity. Subjective assessments by parents/guardians indicated that ADHD symptoms improved significantly. There was also significant improvement in the number of correct responses and interference rates in the reverse Stroop task. Furthermore, postintervention PFC activity was significantly higher. These results suggest that the STP improved inhibitory control in executive function, which is considered as a key symptom of ADHD. The increase in PFC activity further suggests that the STP improves cognition through neural function.

${ }^{*}$ Corresponding author.

How to cite this paper: Yasumura, A., Yuge, K., Egami, C., Anai, C., Mukasa, A., Yamashita, Y. and Inagaki, M. (2016) Behavioral and Neural Enhancing Effects of a Summer Treatment Program in Children with Attention Deficit Hyperactivity Disorder. Open Journal of Pediatrics, 6, 91-99. http://dx.doi.org/10.4236/ojped.2016.61015 


\section{Keywords}

\section{Attention Deficit Hyperactivity Disorder (ADHD), Inhibitory Control, Prefrontal Cortex, Behavioral Treatment, Reverse Stroop Task, Near-Infrared Spectroscopy}

\section{Introduction}

Attention-deficit/hyperactivity disorder (ADHD) is a neuro-developmental disorder whose main symptoms are inattention, hyperactivity, and impulsivity [1]. It has been argued that the core symptom of ADHD is deficiency in executive functioning [2] [3], in which the prefrontal cortex (PFC) has a significant role [4]-[8]. Moreover, secondary disorders, such as personality disorders, tend to occur if there is no timely intervention to address the core symptom of ADHD; therefore, early identification and treatment is critical [9]-[11].

Interventions for ADHD primarily involve medication, behavioral modification treatment, and more recently, neurofeedback. Medication is reported to improve behavior and increase PFC activity [12]-[17]. Behavioral treatment, however, has the advantage that it has no side effects and can be administered relatively safely to children [18]. However, although behavioral treatment reportedly improves behavior, there are few reports on its efficacy in improving neural function. Given that behavioral treatment is useful in early intervention, there is a need to clarify its impact on the PFC, which is deeply related to the core symptom of ADHD.

This study examined the neural and behavioral effects of a behavioral treatment program on PFC activity. We focused on the 2-week Kurume summer treatment program (STP), which was based on Pelham's American STP, administered to children with ADHD every year in Kurume City, Fukuoka, Japan. The Kurume STP provides children with ADHD with a summer camp experience that focuses on improving behavior, motor abilities, and social skills [19]. During the program, behavioral treatment is administered to help the children control their inattention, hyperactivity, and impulsivity, and to learn appropriate behavior [13] [14] [20] [21]. Emphasis is placed on controlling behavior and improving sociability through a point system, daily report card, and group work [13] [14]. To determine from a behavioral and neurofunctional perspective how the ADHD core symptom (PFC syndrome) changes between pre- and post-intervention, we used a reverse Stroop task (RST), which assessed inhibitory control. The RST is widely used as an interference control task, which involves executive function regulated primarily by the PFC [22]-[25]. In a previous study that compared children with ADHD with typically developing children, it was found that RST results reflected the particular characteristics of ADHD, suggesting that it is highly useful as an objective index in intervention studies [3].

\section{Material and Methods}

\subsection{Participants}

We recruited children with ADHD who took part in the STP in 2013 and 2014. All of them were born in Fukuoka or Saga prefecture, Japan. ADHD diagnosis was provided by a pediatric neurologist specializing in developmental disorders, and was based on the Diagnostic and Statistical Manual of Mental Disorders Fourth Edition, Text Revised and Fifth Edition (DSM-IV-TR and 5) [1]. Each of the children scored more than 80 on the full intelligence quotient of the Wechsler Intelligence Scale for Children-III (WISC-III) or the WISC-IV [26]. After excluding children for whom the task could not be implemented satisfactorily or whose artifacts were very large (>2 standard deviations), 20 children remained (mean age: 9.72 years old; male children: 17; see Table 1). Of these participants, 14 were receiving medication before the intervention, and the same number were receiving medication after intervention. All the participants and their guardians provided written informed consent before the experiment. The protocol was approved by the Ethics Committee of the National Center of Neurology and Psychiatry and Kurume University School of Medicine. The assessments were carried out in accordance with the approved guidelines.

\subsection{Psychological Examination}

To assess non-verbal intelligence, we administered Raven's Colored Progressive Matrices pre- and post- intervention. To assess reading comprehension, we administered the reading comprehension subtest of the Kaufman 
Table 1. Participants' scores on behavioral tests.

\begin{tabular}{|c|c|c|c|c|}
\hline & $\begin{array}{l}\text { Pre-intervention } \\
\quad(\mathrm{n}=20)\end{array}$ & $\begin{array}{l}\text { Post-intervention } \\
\qquad(\mathrm{n}=20)\end{array}$ & $\begin{array}{c}t \text { value } \\
(d f=19)\end{array}$ & $p$ value \\
\hline Age & $\begin{array}{c}9.72 \\
(1.27)\end{array}$ & $\begin{array}{c}9.89 \\
(1.27)\end{array}$ & & \\
\hline $\begin{array}{l}\text { Non-verbal } \\
\text { intelligence }\end{array}$ & $\begin{array}{l}27.35 \\
(3.62)\end{array}$ & $\begin{array}{l}28.45 \\
(5.54)\end{array}$ & 1.37 & 0.186 \\
\hline Reading comprehension & $\begin{array}{l}17.90 \\
(4.52)\end{array}$ & $\begin{array}{l}18.30 \\
(4.32)\end{array}$ & 0.801 & 0.433 \\
\hline Inattention & $\begin{array}{l}16.50 \\
(5.61)\end{array}$ & $\begin{array}{l}12.85 \\
(5.83)\end{array}$ & 5.45 & $<0.001$ \\
\hline $\begin{array}{c}\text { Hyperactivity } \\
\text { /impulsivity }\end{array}$ & $\begin{array}{l}10.00 \\
(6.32)\end{array}$ & $\begin{array}{c}7.50 \\
(6.17)\end{array}$ & 3.58 & 0.002 \\
\hline ODD & $\begin{array}{c}9.50 \\
(5.58)\end{array}$ & $\begin{array}{c}6.90 \\
(5.51)\end{array}$ & 4.37 & $<0.001$ \\
\hline
\end{tabular}

Mean values of clinical scales. Standard deviations are shown in parentheses. ODD = Oppositional defiant disorder.

Assessment Battery for Children (K-ABC) pre- and post-intervention [3] [27].

\subsection{Rating Scale}

To determine the correlation between age and ADHD severity, we asked all the children's parents/guardians to complete the Swanson, Nolan, and Pelham IV scale (SNAP-IV) [28]. The SNAP is a version of the DSM-based ADHD-Rating Scale that includes items for measuring oppositional defiant disorder (ODD).

\subsection{Inhibitory Control Task}

We administered the RST, which employs color reading interference control as a behavioral index, and measured the interference rate. The procedures for the task and analysis were in accordance with the protocols of Yasumura et al. [3]. The participants sat approximately $50 \mathrm{~cm}$ in front of a 38-cm (15-inch) liquid crystal display screen with a gray background. The tasks employed a touch panel screen. All words on the screen were displayed in Japanese.

\subsection{Recording and Analysis}

While the participants performed the RST, neural activity in the PFC was recorded by measuring changes in oxygenated hemoglobin (oxy-Hb) using a multichannel near-infrared spectroscopy (NIRS) system (OEG-16; Spectratech Inc., Tokyo, Japan). The tasks, as well as the procedures for the analysis, were in accordance with the protocols of Yasumura et al. [3]. In this system, near-infrared laser diodes with two wavelengths (approximately 770 and $840 \mathrm{~nm}$ ) were used to emit near-infrared light. The re-emitted light was detected with avalanche photodiodes located $30 \mathrm{~mm}$ from the emitters. The temporal resolution of acquisition was $0.65 \mathrm{~s}$. The system measures oxy- $\mathrm{Hb}$ at a depth of approximately $30 \mathrm{~mm}$ below the scalp. In our system, six emitters and six detectors were placed at alternate points on a $2 \times 6$ grid, enabling us to detect signals from 16 channels (Figure 1). The center of the probe matrix was placed on Fpz (international 10 - 10 system), and the bottom left and bottom right corners were located around F7 and F8, respectively, following a previous report [3] [29]-[31]. The NIRS signals were sent to a data collection computer. To increase the signal-to-noise ratio, each record was converted to a z-score to compare traces across the participants and channels [32]-[34]. For the analysis, we conducted paired t-tests on the pre- and post-intervention results as behavioral and physiological indices. The level chosen for alpha was 0.05 .

\section{Results}

\subsection{Psychological Examination}

We did not observe any significant difference in non-verbal intelligence or reading ability between pre- and 
post-intervention $(\mathrm{t}(19)=1.37, \mathrm{p}=0.19 ; \mathrm{K}-\mathrm{ABC}: \mathrm{t}(19)=0.80, \mathrm{p}=0.43)$.

\subsection{Rating Scale}

There was significant improvement from pre- to post-intervention in the SNAP subscales of inattention, hyperactivity/impulsivity, and ODD (inattention: $\mathrm{t}(19)=5.45, \mathrm{p}<0.001$; hyperactivity/impulsivity: $\mathrm{t}(19)=3.58, \mathrm{p}=$ 0.002; ODD: $\mathrm{t}(19)=4.37, \mathrm{p}<0.001$; see Table 1 ).

\subsection{Behavior}

Regarding the RST results, there was no significant difference in the number of correct responses under the nonincongruent (neutral stimuli) condition. However, under the interference (incongruent stimuli) condition, there was significant improvement between pre- and post-intervention (neutral: $t(19)=0.15, \mathrm{p}=0.88$; incongruent: $\mathrm{t}(19)=2.11, \mathrm{p}=0.049$ ). There was also a significant improvement in interference rate between pre- and postintervention $(\mathrm{t}(19)=2.16, \mathrm{p}=0.044$; Figure 2 and Figure 3$)$.

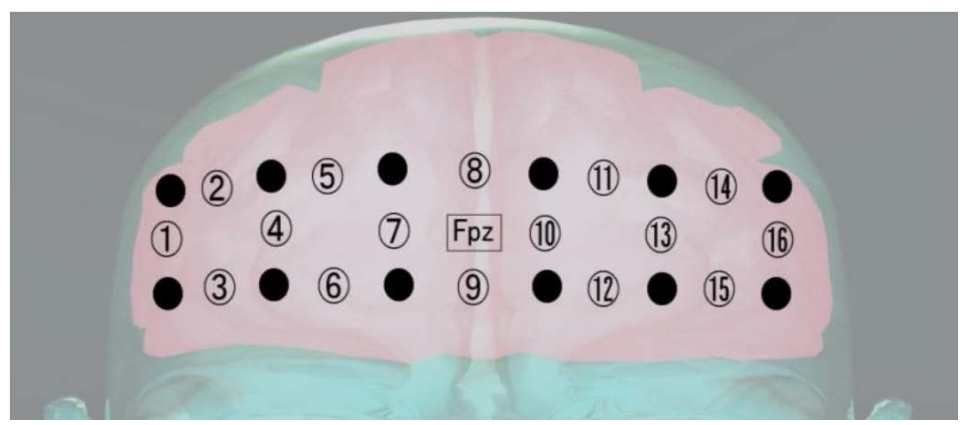

Figure 1. Emitter and probe configuration for the NIRS. The NIRS system was attached to the prefrontal area. The center of the probe matrix was placed on Fpz (International 10 - 10 system).

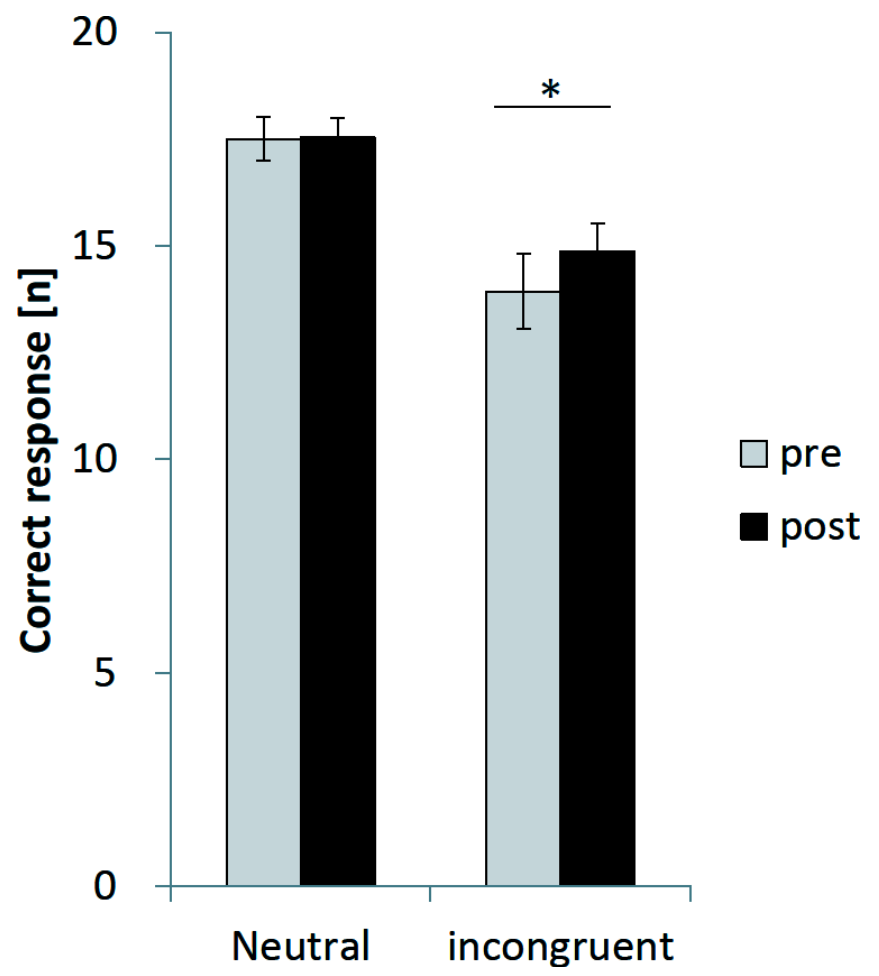

Figure 2. Behavioral results of the reverse-Stroop test. The number of correct responses for each condition during the task. Error bars indicate standard errors. ${ }^{*} \mathrm{p}<0.05$. 


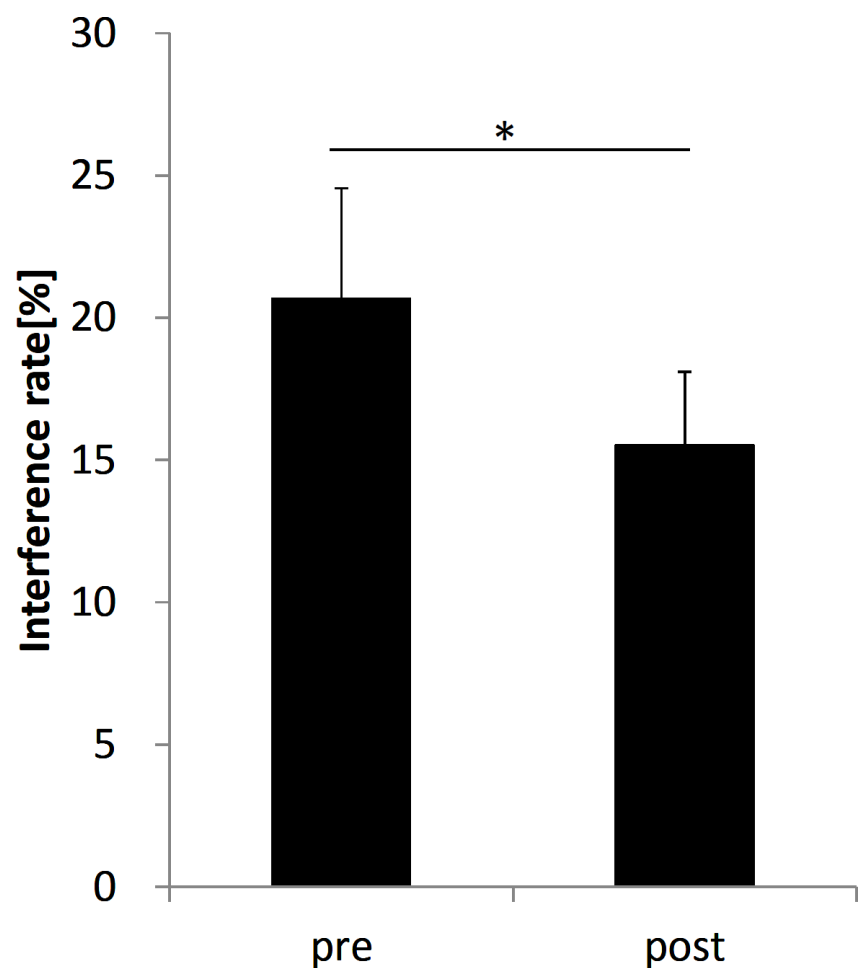

Figure 3. Behavioral results of the reverse-Stroop test. The interference rate for preand post-intervention during the task. Error bars indicate standard errors. ${ }^{*} \mathrm{p}<0.05$.

\subsection{Brain Function}

We compared each channel pre- and post-intervention and found that activity in the left PFC channel 13 increased significantly (ch13: $\mathrm{t}(19)=2.16, \mathrm{p}<0.044)$. We also observed a trend for improvement in the right PFC channel 2 (ch2: $t(19)=1.94, p=0.067$; see Figure 4). The other channels did not yield significant changes $(\mathrm{p}>$ $0.1)$.

\section{Discussion}

\subsection{Rating Scale}

All the SNAP items—inattention, hyperactivity/impulsivity, and ODD—showed an improvement post- intervention. Subjective assessments by parents/guardians indicated that ADHD symptoms improved significantly. Hyperactivity/impulsivity and ODD improved to below their respective cutoff scores of 9 and 8 . However, inattention remained approximately 4 points above the cutoff even after intervention, showing inadequate improvement. Given that the scores for hyperactivity/impulsivity and ODD were around 1 point above the cutoff before intervention, the above results were probably due to the presence of participants whose predominant symptom was inattention. Indeed, inattention decreased by around 4 points, making it the symptom that improved the most. Moreover, as inattention is more likely to persist into adulthood than is hyperactivity/impulsivity, the fact that inattention decreased significantly after the program demonstrated the efficacy of the intervention [10] [35].

\subsection{Behavior}

Regarding the number of correct responses for the RST, we did not observe any improvement between pre- and post-intervention under the non-incongruent/neutral condition; however, we observed a significant improvement between pre- and post-intervention under the incongruent condition. We also observed a significant improvement in interference rates between pre- and post-intervention. This finding suggests that the interference rate in the RST has a particularly close association with the core factor of ADHD—inhibitory control [3] [24] [36]. It should be noted, however, that we did not observe any pre- or post-intervention changes in non-verbal intelli- 


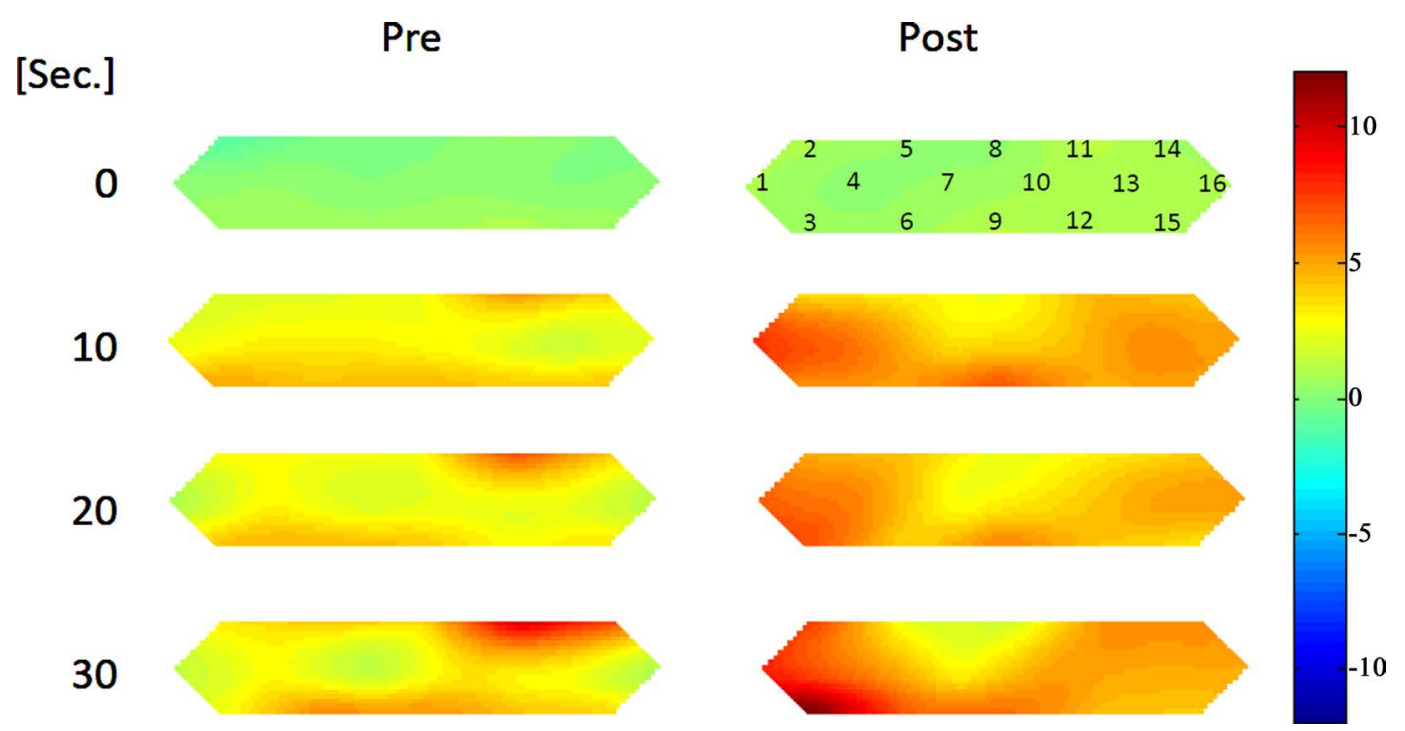

Figure 4. Mean z-score changes in oxygenated hemoglobin (oxy-Hb) measured by near-infrared spectroscopy during the reverse Stroop task. Pseudocolor images plot regional changes in oxy-Hb for pre- and post-intervention during the task. Values on the first row of the first image indicate the channel locations.

gence or reading comprehension. In light of these results, we surmise that interference control, as the core factor of ADHD, improved as a result of the intervention.

\subsection{Brain Function}

We compared PFC activity pre- and post-intervention and found that PFC activity in the left and right channels were improved after the STP. It has been reported that inhibitory control is strongly related to activity in the right PFC [37]. In the present study, the post-intervention brain topography revealed low activity in the right channels of the PFC. A previous study reported that the severity of the core ADHD symptom is negatively associated with activity in the right PFC [3] (Figure 4). The brain topography in the present study also revealed that PFC activity overall improved from pre-intervention, suggesting that the increase in PFC activity post-intervention reflected behavioral improvement, as measured by the inhibitory task (Figure 4). A recent study suggested that left PFC activity during an attention-demanding cognitive task was abnormal before treatment but normalized following behavioral treatment for chronic lower back pain [38]. Thus, improvement in the activation of the right and left PFC might be due to the behavioral treatment provided during the STP that, for instance, improved self-monitoring.

This is the first study to report that behavioral treatment improves PFC activity in children with ADHD [15] [16]. The assumption that PFC dysfunction is the core symptom of ADHD implies that neurotransmitters such as dopamine and norepinephrine have a key role [39]. This would also imply that behavioral treatment during the STP brought about a neurophysiological change. Future studies need to clarify connections with brain areas outside the PFC [7] [40]. In addition, another non-drug-based intervention—namely, neurofeedback—has come to be recognized as suitable for children with ADHD. Thus, there is also a need to compare the outcome of behavioral treatment with that of other non-drug-based interventions [12] [17].

\section{Limitations}

When assessing treatment outcomes, the influence of medication should be considered; however, in the present study, the number of children taking medication was the same pre- and post-intervention, suggesting that medication had a limited effect on the results. In addition, the assessment period was only 2 months long, so participants' development likely had minimal impact on the results [41]. Lastly, this study involved a comparison among a single group; thus, so it would be desirable to compare the results with typically developing children or verify the results with a crossover test. There is also a need to examine the long-term efficacy of the intervention. 


\section{Conclusion}

We verified the efficacy of the 2-week Kurume STP by measuring changes in inhibitory control—an executive function - from a behavioral and physiological perspective. The results revealed improvements in behavior and PFC activity. These results provide neurological evidence for the efficacy of behavioral treatment that, unlike medication, has no concerning side effects.

\section{Acknowledgments}

This work was supported in part by the TMC Young Investigator Fellowship and an Intramural Research Grant (25 - 6; Clinical Research for Diagnostic and Therapeutic Innovations in Developmental Disorders) for Neurological and Psychiatric Disorders of the National Center of Neurology and Psychiatry, a Grant-in-Aid for Young Scientists (A) from the Japan Society for the Promotion of Science KAKENHI (15H05405 to Akira Yasumura), and a Grant-in-Aid for Challenging Exploratory Research from the Japan Society for the Promotion of Science KAKENHI (15K13167 to Akira Yasumura).

\section{Conflict of Interest}

The authors declare that they have no conflict of interest.

\section{References}

[1] American Psychiatric Association (2013) Diagnostic and Statistical Manual of Mental Disorders (DSM-5). 5th Edition, American Psychiatric Publishing, Washington DC.

[2] Barkley, R.A. (1997) Behavioral Inhibition, Sustained Attention, and Executive Functions: Constructing a Unifying Theory of ADHD. Psychological Bulletin, 121, 65-94. http://dx.doi.org/10.1037/0033-2909.121.1.65

[3] Yasumura, A., Kokubo, N., Yamamoto, H., Yasumura, Y., Nakagawa, E., Kaga, M., et al. (2014) Neurobehavioral and Hemodynamic Evaluation of Stroop and Reverse Stroop Interference in Children with attention-Deficit/Hyperactivity Disorder. Brain Development, 36, 97-106. http://dx.doi.org/10.1016/j.braindev.2013.01.005

[4] Barkley, R.A., Grodzinsky, G. and DuPaul, G.J. (1992) Frontal Lobe Functions in Attention Deficit Disorder with and without Hyperactivity: A Review and Research Report. Journal of Abnormal Child Psychology, 20, 163-188. http://dx.doi.org/10.1007/BF00916547

[5] Faraone, S.V. and Biederman, J. (1998) Neurobiology of Attention-Deficit Hyperactivity Disorder. Biological Psychiatry, 44, 951-958. http://dx.doi.org/10.1016/S0006-3223(98)00240-6

[6] Castellanos, F.X., Giedd, J.N., Berquin, P.C., Walter, J.M., Sharp, W., Tran, T., et al. (2001) Quantitative Brain Magnetic Resonance Imaging in Girls with Attention-Deficit/Hyperactivity Disorder. Archives of General Psychiatry, 58, 289-295. http://dx.doi.org/10.1001/archpsyc.58.3.289

[7] Cingulate, B.G. (2011) Frontal, and Parietal Cortical Dysfunction in Attention-Deficit/Hyperactivity Disorder. Biological Psychiatry, 69, 1160-1167. http://dx.doi.org/10.1016/j.biopsych.2011.01.022

[8] da Silva, N., Szobot, C.M., Anselmi, C.E., Jackowski, A.P., Chi, S.M., Hoexter, M.Q., et al. (2011) Attention Deficit/ Hyperactivity Disorder: Is There a Correlation between Dopamine Transporter Density and Cerebral Blood Flow? Clinical Nuclear Medicine, 36, 656-660. http://dx.doi.org/10.1097/rlu.0b013e318219b49d

[9] Kasen, S., Cohen, P., Skodol, A.E., Johnson, J.G. and Brook, J.S. (1999) Influence of Child and Adolescent Psychiatric Disorders on Young Adult Personality Disorder. The American Journal of Psychiatry, 156, 1529-1535. http://dx.doi.org/10.1176/ajp.156.10.1529

[10] Faraone, S.V., Biederman, J., Spencer, T., Wilens, T., Seidman, L.J., Mick, E., et al. (2000) Attention-Deficit/Hyperactivity Disorder in Adults: An Overview. Biological Psychiatry, 48, 9-20. http://dx.doi.org/10.1016/S0006-3223(00)00889-1

[11] Lampe, K., Konrad, K., Kroener, S., Fast, K., Kunert, H.J. and Herpertz, S.C. (2007) Neuropsychological and Behavioural Disinhibition in Adult ADHD Compared to Borderline Personality Disorder. Psychological Medicine, 37, 1717-1729. HTTP://DX.DOI.ORG/10.1017/S0033291707000517

[12] Strehl, U., Leins, U., Goth, G., Klinger, C., Hinterberger, T. and Birbaumer, N. (2006) Self-Regulation of Slow Cortical Potentials: A New Treatment for Children with Attention-Deficit/Hyperactivity Disorder. Pediatrics, 118, e1530e1540. http://dx.doi.org/10.1542/peds.2005-2478

[13] Yamashita, Y., Mukasa, A., Honda, Y., Anai, C., Kunisaki, C., Koutaki, J., et al. (2010) Short-Term Effect of American Summer Treatment Program for Japanese Children with Attention Deficit Hyperactivity Disorder. Brain Develop- 
ment, 32, 115-122. http://dx.doi.org/10.1016/j.braindev.2008.12.004

[14] Yamashita, Y., Mukasa, A., Anai, C., Honda, Y., Kunisaki, C., Koutaki, J., et al. (2011) Summer Treatment Program for Children with Attention Deficit Hyperactivity Disorder: Japanese Experience in 5 Years. Brain Development, 33, 260-367. http://dx.doi.org/10.1016/j.braindev.2010.09.005

[15] Monden, Y., Dan, H., Nagashima, M., Dan, I., Kyutoku, Y., Okamoto, M., et al. (2012) Clinically-Oriented Monitoring of Acute Effects of Methylphenidate on Cerebral Hemodynamics in ADHD Children Using fNIRS. Clinical Neurophysiology, 123, 1147-1157. http://dx.doi.org/10.1016/j.clinph.2011.10.006

[16] Nagashima, M., Monden, Y., Dan, I., Dan, H., Tsuzuki, D., Mizutani, T., et al. (2014) Acute Neuropharmacological Effects of atomoxetIne on Inhibitory Control in ADHD Children: A fNIRS Study. NeuroImage: Clinical, 6, 192-201. http://dx.doi.org/10.1016/j.nicl.2014.09.001

[17] Takahashi, J., Yasumura, A., Nakagawa, E. and Inagaki, M. (2014) Changes in Negative and Positive EEG Shifts during Slow Cortical Potential Training in Children with Attention-Deficit/Hyperactivity Disorder: A Preliminary Investigation. Neuroreport, 25, 618-624. http://dx.doi.org/10.1097/wnr.0000000000000156

[18] Efron, D., Jarman, F. and Barker, M. (1997) Side Effects of Methylphenidate and Dexamphetamine in Children with Attention Deficit Hyperactivity Disorder: A Double-Blind, Crossover Trial. Pediatrics, 100, 662-666. http://dx.doi.org/10.1542/peds.100.4.662

[19] Pelham, W.E. and Fabiano, G.A. (2008) Evidence-Based Psychosocial Treatments for Attention-Deficit/Hyperactivity Disorder. Journal of Clinical Child \& Adolescent Psychology, 37, 184-214. http://dx.doi.org/10.1080/15374410701818681

[20] Frazier, S.L., Chacko, A., Van Gessel, C., O’Boyle, C. and Pelham, W.E. (2012) The Summer Treatment Program Meets the South Side of Chicago: Bridging Science and Service in Urban After-School Programs. Child and Adolescent Mental Health, 17, 86-92. http://dx.doi.org/10.1111/j.1475-3588.2011.00614.x

[21] Fabiano, G.A., Schatz, N.K. and Pelham, W.E. (2014) Summer treatment programs for youth with ADHD. Child \& Adolescent Psychiatric Clinics, 23, 757-773. http://dx.doi.org/10.1016/j.chc.2014.05.012

[22] Ruff, C.C., Woodward, T.S., Laurens, K.R. and Liddle, P.F. (2001) The Role of the Anterior Cingulate Cortex in Conflict Processing: Evidence from Reverse Stroop Interference. Neuroimage, 14, 1150-1158. http://dx.doi.org/10.1006/nimg.2001.0893

[23] Ikeda, Y., Hirata, S., Okuzumi, H. and Kokubun, M. (2010) Features of Stroop and Reverse-Stroop Interference: Analysis by Response Modality and Evaluation. Perceptual and Motor Skills, 110, 654-60. http://dx.doi.org/10.2466/pms.110.2.654-660

[24] Song, Y. and Hakoda, Y. (2011) An Asymmetric Stroop/Reverse-Stroop Interference Phenomenon in ADHD. Journal of Attention Disorders, 15, 499-505. http://dx.doi.org/10.1177/1087054710367607

[25] Ikeda, Y., Okuzumi, H. and Kokubun, M. (2013) Age-Related Trends of Stroop-Like Interference in Animal Size Tests in 5- to 12-Year-Old Children and Young Adults. Child Neuropsychology, 19, 276-291. http://dx.doi.org/10.1080/09297049.2012.658364

[26] Wechsler, D. (1991) Manual for Wechsler Intelligence Scale for Children. 3rd Edition, The Psychological Corporation, San Antonio.

[27] Raven, J. (1976) Coloured Progressive Matrices: Sets A, Ab, B. OPP Ltd., Oxford.

[28] Bussing, R., Fernandez, M., Harwood, M., Hou, W ., Garvan, C.W., Eyberg, S.M., et al. (2008) Parent and Teacher SNAP-IV Ratings of Attention Deficit Hyperactivity Disorder Symptoms: Psychometric Properties and Normative Ratings from a School District Sample. Assessment, 15, 317-328. http://dx.doi.org/10.1177/1073191107313888

[29] Kita, Y., Gunji, A., Inoue, Y., Goto, T., Sakihara, K., Kaga, M., et al. (2011) Self-Face Recognition in Children with Autism Spectrum Disorders: A Near-Infrared Spectroscopy Study. Brain \& Development, 33, 494-503. http://dx.doi.org/10.1016/j.braindev.2010.11.007

[30] Yasumura, A., Kokubo, N., Yamamoto, H., Yasumura, Y., Moriguchi, Y., Nakagawa, E., et al. (2012) Neurobehavioral and Hemodynamic Evaluation of Cognitive Shifting in Children with Autism Spectrum Disorder. Journal of Behavioral and Brain Science, 2, 463-470. http://dx.doi.org/10.4236/jbbs.2012.24054

[31] Yasumura, A., Inagaki, M. and Hiraki, K. (2014) Relationship between Neural Activity and Executive Function: An NIRS Study. SRN Neuroscience, 2014, Article ID: 734952. http://dx.doi.org/10.1155/2014/734952

[32] Matsuda, G. and Hiraki, K. (2006) Sustained Decrease in Oxygenated Hemoglobin during Video Games in the Dorsal Prefrontal Cortex: A NIRS Study of Children. Neuroimage, 29, 706-711. http://dx.doi.org/10.1016/j.neuroimage.2005.08.019

[33] Shimada, S. and Hiraki, K. (2006) Infant's Brain Responses to Live and Televised Action. Neuroimage, 32, $930-939$. http://dx.doi.org/10.1016/j.neuroimage.2006.03.044 
[34] Moriguchi, Y. and Hiraki, K. (2009) Neural Origin of Cognitive Shifting in Young Children. Proceedings of the National Academy of Sciences of the United States of America, 106, 6017-6021. http://dx.doi.org/10.1073/pnas.0809747106

[35] Sonuga-Barke, E.J. (2002) Psychological Heterogeneity in AD/HD—A Dual Pathway Model of Behaviour and Cognition. Behavioural Brain Research, 130, 29-36. http://dx.doi.org/10.1016/S0166-4328(01)00432-6

[36] Ikeda, Y., Okuzumi, H. and Kokubun, M. (2013) Stroop/Reverse-Stroop Interference in Typical Development and Its Relation to Symptoms of ADHD. Research in Developmental Disabilities, 34, 2391-2398. http://dx.doi.org/10.1016/j.ridd.2013.04.019

[37] Aron, A.R., Robbins, T.W. and Poldrack, R.A. (2004) Inhibition and the Right Inferior Frontal Cortex. Trends in Cognitive Science, 8, 170-177. http://dx.doi.org/10.1016/j.tics.2004.02.010

[38] Seminowicz, D.A., Wideman, T.H., Naso, L., Hatami-Khoroushahi, Z., Fallatah, S., Ware, M.A., et al. (2011) Effective Treatment of Chronic Low Back Pain in humans Reverses Abnormal Brain Anatomy and Function. Journal of Neuroscience, 31, 7540-7550. http://dx.doi.org/10.1523/JNEUROSCI.5280-10.2011

[39] Arnsten, A.F. and Li, B.M. (2005) Neurobiology of Executive Functions: Catecholamine Influences on Prefrontal Cortical Functions. Biological Psychiatry, 57, 1377-1384. http://dx.doi.org/10.1016/j.biopsych.2004.08.019

[40] Makris, N., Biederman, J., Monuteaux, M.C. and Seidman, L.J. (2009) Towards Conceptualizing a Neural SystemsBased Anatomy of Attention-Deficit/Hyperactivity Disorder. Developmental Neuroscience, 31, 36-49. http://dx.doi.org/10.1159/000207492

[41] Ikeda, Y., Okuzumi, H., Kokubun, M. and Haishi, K. (2011) Age-Related Trends of Interference Control in SchoolAge Children and Young Adults in the Stroop Color-Word Test. Psychological Reports, 108, 577-584. http://dx.doi.org/10.2466/04.10.22.PR0.108.2.577-584 